\title{
Conformational Mobility in Alkyl-Chains of an
}

\author{
Anchored Bilayer
}

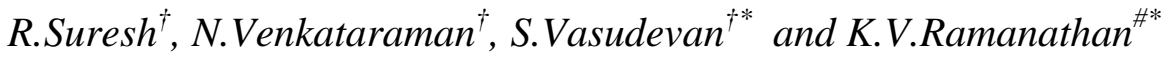

\section{Supplementary Information}

1.X-ray diffraction patterns of the anchored bilayer, $\mathrm{Cd}_{0.83} \mathrm{PS}_{3}(\mathrm{CTA})_{0.34}$, recorded at different temperatures.

2. Methylene stretching modes in the infrared spectrum of the anchored bilayer, $\mathrm{Cd}_{0.83} \mathrm{PS}_{3}(\mathrm{CTA})_{0.34}$ at different temperatures.

3. Position of the methylene symmetric and anti-symmetric stretching modes of the anchored bilayer, $\mathrm{Cd}_{0 \cdot 83} \mathrm{PS}_{3}(\mathrm{CTA})_{0.34}$ at different temperatures. 


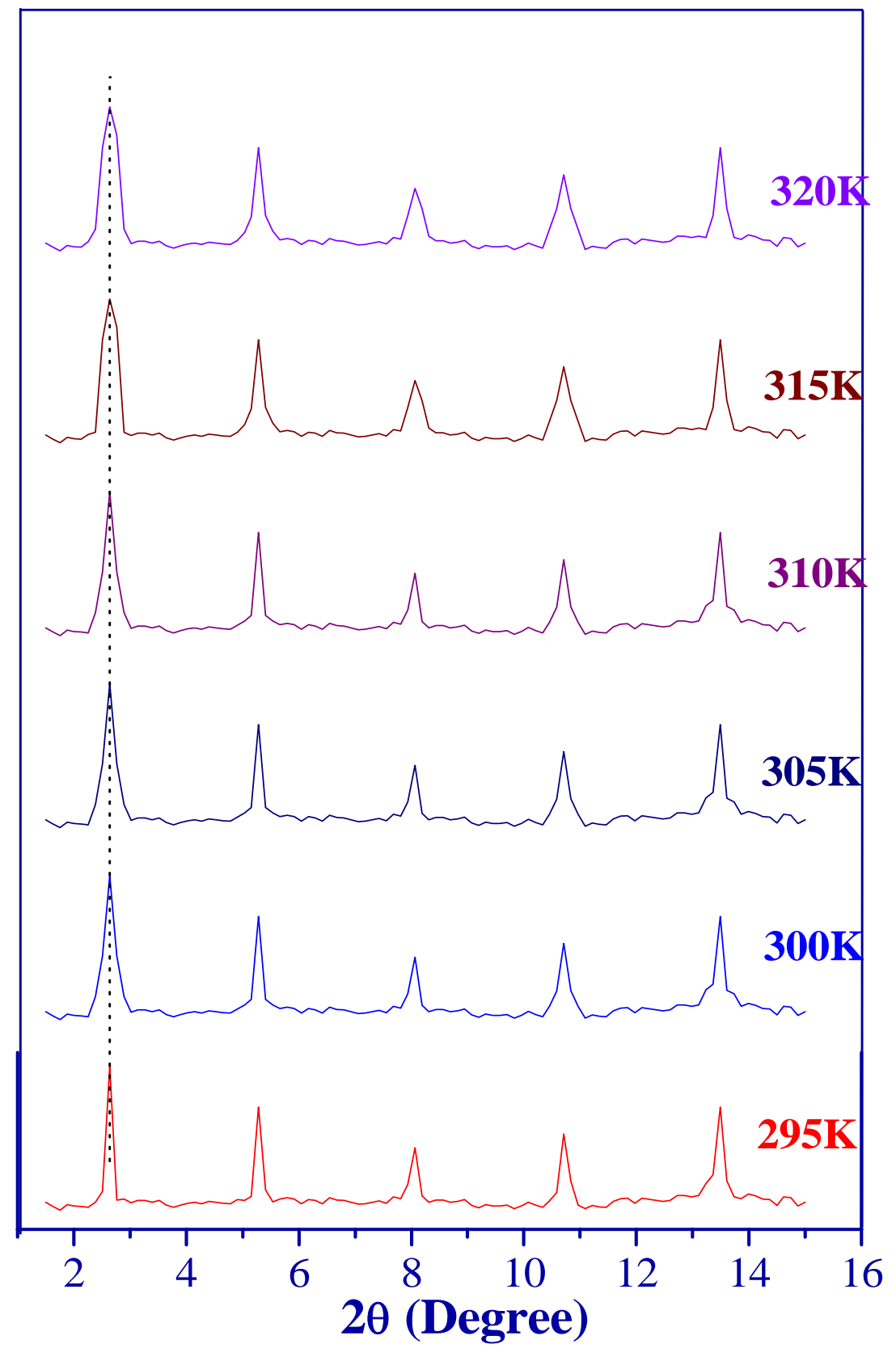

Figure :X-ray diffraction patterns of the anchored bilayer, $\mathrm{Cd}_{0.83} \mathrm{PS}_{3}(\mathrm{CTA})_{0.34}$. at different temperatures 


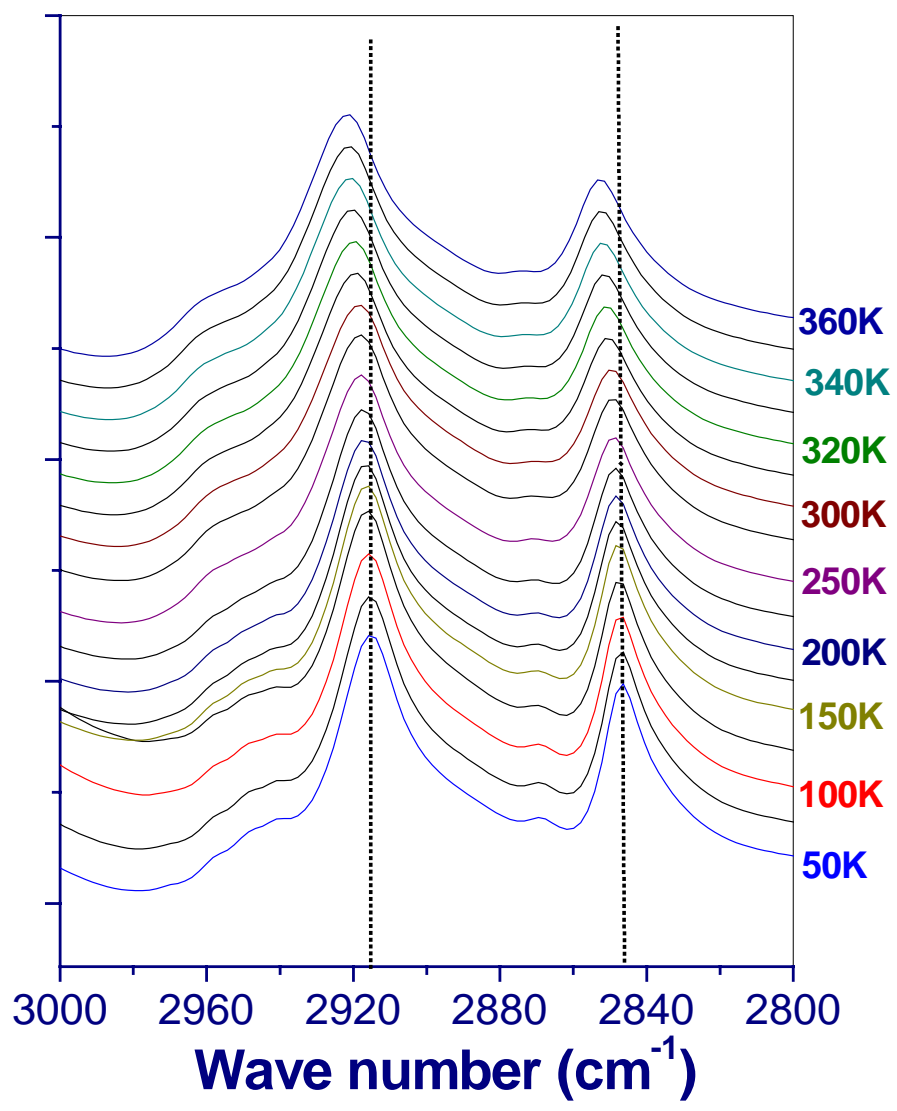

Figure: Methylene stretching modes of the anchored bilayer, $\mathrm{Cd}_{0.83} \mathrm{PS}_{3}(\mathrm{CTA})_{0.34}$ recorded at different temperatures.

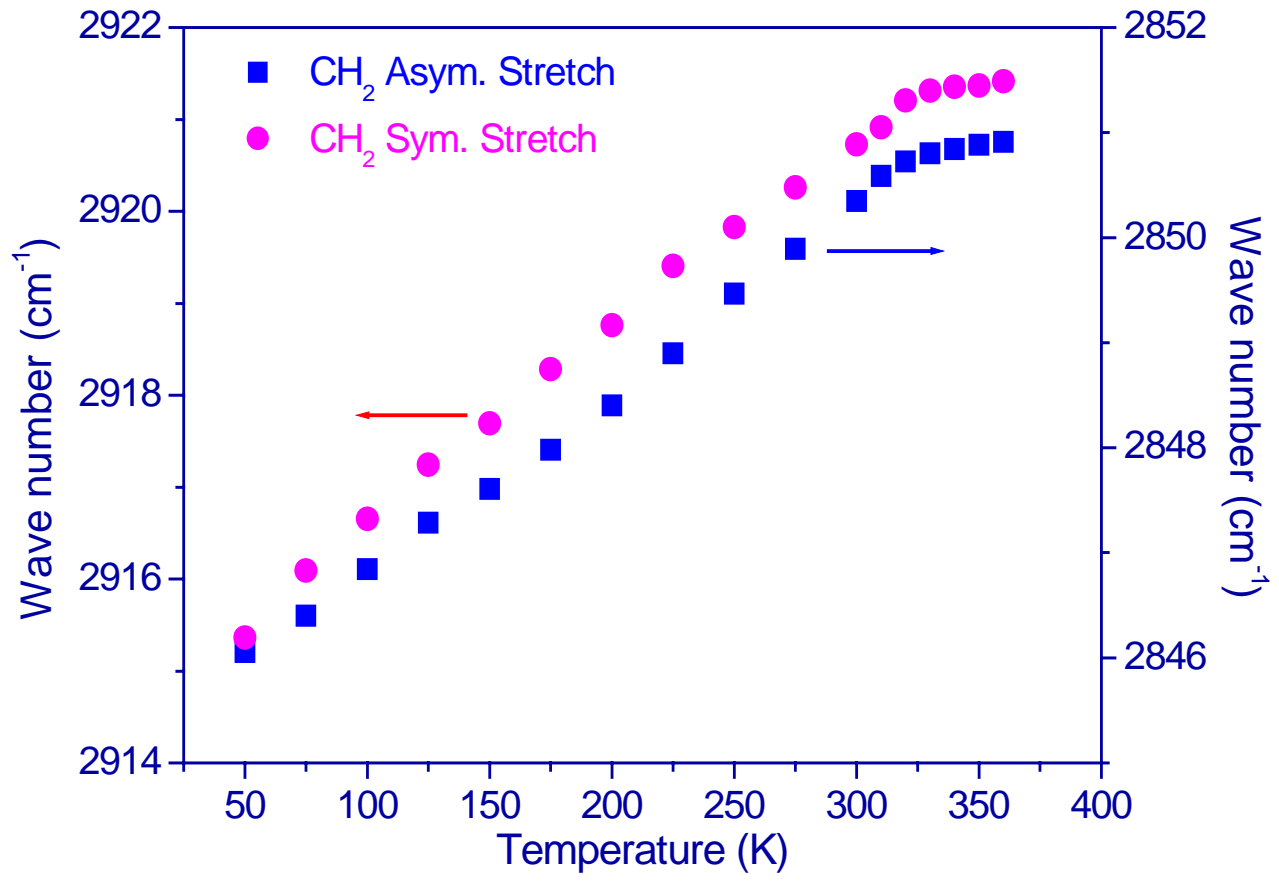

Figure: Position of the methylene symmetric and anti-symmetric stretching modes of the anchored bilayer, $\mathrm{Cd}_{0.83} \mathrm{PS}_{3}(\mathrm{CTA})_{0.34}$ at different temperatures 